\title{
Discussion on Post - evaluation of Land Reclamation Project in Coal Mining Subsidence Land
}

\author{
Hui Zhang ${ }^{1}$, Feng Gao ${ }^{2}$ \\ ${ }^{1}$ Department of Economics and Management, Jining University, Qufu Shandong, 273155, China \\ ${ }^{2}$ Jining City Land Resources Bureau, Jining Shandong, 272100, China
}

Keywords: Coal mining collapse, Land reclamation, Post evaluation mechanism.

\begin{abstract}
With the growth of economy and the progress of society, China's land development and consolidation project have become an important path for the balance of cultivated land in China at present. It needs the relevant departments to optimize the situation in accordance with the actual situation. Among them, due to the impact of subsidence settlement, terrain crushing problems will appear in some coal mining areas to varying degrees, and even serious soil nutrient loss appear. Therefore, the relevant departments ought to carry out land reclamation projects and implement land management mechanism while optimize the rasterization processing effect at the same time. In this paper, the process of the post evaluation of the land reclamation project in the mining subsidence area is analyzed, so is the application path of implementing concrete measures in the actual project in combination with the project, which is aimed at providing more valuable reference suggestions for the technical management department.
\end{abstract}

\section{Introduction}

Coal mine underground mining in China occupies about $97 \%$ of the total amount of raw coal and the most basic mining method is the full subsidence method of long wall face, that is, the effective management of roof structure, but this method will lead to large-scale collapse of coal mines. Therefore, the mining subsidence area is the underground mining area formed after the underground coal seam mining, because the whole structure is out of balance after the original terrain balance is broken and the overburden structure has been seriously affected. There are not only structural deformation and fracture, but also damage and deformation, which leads to tilt and tensile deformation of the surface. Based on that, the surface of the crack structure and high and low gradient problems are serious. In addition, the effect of nutrient retention and the structure of physical and chemical properties in the region are also ineffective, which require centralized integration and comprehensive analysis of the soil by the agricultural management department.

\section{Evaluation process of land reclamation project after mining subsidence}

\section{Determine the factor set}

In the process of using the entropy weight to make a fuzzy comprehensive evaluation of the structure, the most important thing is to focus on the factor set to determine and fundamentally optimize its processing effect in order to achieve a comprehensive upgrade of the management system. The factors mentioned here mainly refer to the consideration of the problem, and it is necessary to evaluate the factors in order to establish a different basis for judging the index factors, and set the number of index factors as $\mathrm{n}$, each indicator factor being $U_{1}, U_{2}, \ldots, U_{n}$ that are recorded as a factor set $U=\left\{U_{1}, U_{2}, \ldots, U_{n}\right\}$. In other words, the different parameters of the factor concentration can effectively summarize or describe the specific problems, thus simplifying the evaluation process.

First, the economic post-evaluation factor. In the post evaluation project of the land reclamation project of the coal mining subsidence, we must use the concrete economic index to ensure the 
concentration analysis and integration of the investment. To effectively investigate the profitability and economic value of the land reclamation project in the mining subsidence area, we need to comprehensively analyze the cost unit, the income unit and the risk level, and focus the research on the industrial correlation degree as only the comprehensive assessment of the indirect cost and the direct cost can realize the net income calculation result fundamentally in order to ensure that the risk parameters of different reclamation methods can be measured and economic benefits can be optimized. It is important to note that the industrial correlation degree mainly refers to the effect of the land reclamation project on the other industries in the mining subsidence area, which mainly involves the forward correlation and the back correlation, and uses the related index to judge the economic benefit intuitively. Because the application path of the land reclamation project after the mining subsidence is not the same, the industry difference determines the correlation degree difference. If the correlation degree is larger, the pull effect is good and the indirect economic benefit that produces meet the demands; If the correlation degree is smaller, the pull effect is lagging and the indirect economic benefit that produces will get affected;

Second, the ecological post-evaluation factor. In recent years, the Ecological Management index has become an important parameter system in the social economic development project. In the post evaluation of mining subsidence land reclamation project, the ecological post evaluation factor is the basic index of determining the sustainable land use efficiency. In order to determine the regional water resources structure, atmosphere resource structure and entropy parameter, the relevant departments should carry out the land reclamation project of mining subsidence area on the basis of guaranteeing the environmental protection mechanism and the environmental requirement, as well as the agricultural ecological buffering and compensating ability to optimize its ability to resist the bad disaster. Therefore, in the index of ecological evaluation, it focuses on the systematic analysis of air quality, soil fertility and water resources improvement.

Third, the social post evaluation factor is also an important parameter system to measure its sustainable development power. In order to establish a solid foundation for system upgrading and management effect optimization, we should carry out deep analysis and centralized research on concrete management methods, establish an application mechanism to ensure that the social post evaluation mechanism can have far-reaching impact on social environment system, set up sound and effective macroscopic social management mechanism to ensure the integrity of social impact benefit. In addition, the social impact assessment is also the focus of the land consolidation project, involving the improvement of infrastructure, the land security function and the resettlement status of farmers, which have a very important social significance and value.

Finally, the evaluation factor of the process is mainly to evaluate the quality of every major link in the land reclamation project of coal subsidence, analyze and effectively summarize the experience and management effect, deeply integrate the quality management level of engineering construction and fund operation, to ensure the optimization of engineering effect and overall level. In other words, the post-process evaluation factor is a dynamic evaluation mechanism, which needs to be integrated and analyzed, and to focus on the factors that influence the schedule of the project, the project budget and the engineering quality to improve the actual economic benefit of the land reclamation project from the source.

\section{Building hierarchies}

After judging and analyzing the evaluation indexes, we should establish a sound and systematic control mechanism and measures to ensure the integrity of the management model and application mechanism, and also lay a solid foundation for the optimization and upgrading of relevant parameters in the management system. On the basis of the index establishment, this paper analyzes the post evaluation level of the land reclamation project in the mining subsidence area. Among them, the main part includes the economic post evaluation, the ecological evaluation, the social evaluation and so on that are committed to the effective appraisal of reclamation cost, the income, the risk level, the dynamic investment payback period, the mine water resource degree, the farmer resettlement condition, the organization structure system as well as the completion acceptance management . 


\section{Determination of the evaluation set}

According to the relevant requirements and people's specific conditions, the single factors are evaluated in different degrees, so as to establish a pluralistic and multi-angle analysis mechanism to improve the efficiency of information integration, and to ensure that the effect of processing is more comprehensive and effective, as well as to establish a solid foundation for the promotion of system evaluation. The common evaluation set is expressed as $V=\left\{V_{1}, V_{2}, \ldots, V_{m}\right\}$ where $m$ is set as the basic evaluation hierarchy in the set, thus effectively determining the actual problem.

\section{Judging weights set}

In the process of using fuzzy comprehensive evaluation mechanism to set up and judge factor weights, in order to avoid the risk problem, we should make a comprehensive study on the compound effect, effectively optimize the weight effect and effectiveness, and integrate and systematize the different indexes, effectively evade the subjectivity, use the entropy right mechanism and the analytic hierarchy mechanism to analyze and investigate the factor weights. First of all, to conduct a normalization processing of the different indicators and then obtain the matrix structure to make a evaluation of the weight of the object under the index. Secondly, we should determine the index entropy value, and then calculate the difference factor of the index. Finally, the entropy weight value

of the index is determined by the formula $\beta_{i}=\frac{g_{i}}{\sum_{i=1}^{m} g_{i}}$.

\section{Construction of judgment matrix structure}

After the comprehensive analysis of the concrete numerical structure, we should construct the effective matrix structure according to the actual situation of the land reclamation project in the mining subsidence land, and determine the relative importance between the upper level element and the level element, and construct the effective processing mechanism and control measure. In addition, experts, after analyzing the specific issues of the background and data, will integrate the problems reflected, to establish a sound fuzzy evaluation, to achieve the overall optimization of public opinion test results.

\section{Setting the evaluation matrix}

After the fuzzy relation is judged, the membership degree and the weight of factors are synthetically evaluated to ensure that the fuzzy subset of different factors can meet the evaluation $R=\left[\begin{array}{cccc}r_{11} & r_{12} & \ldots & r_{1 \mathrm{~m}} \\ r_{21} & r_{22} & \ldots & r_{2 \mathrm{~m}} \\ \ldots & \ldots & \ldots & \ldots \\ r_{n 1} & r_{n 2} & \ldots & r_{n \mathrm{~m}}\end{array}\right]$.

\section{The project case}

In this paper, the land reclamation project of coal mining subsidence in Shandong Province is taken as an example. The project is a key key project of national investment in 2015, with a total scale of 905 hectares. The project belongs to warm temperate humid sub-humid continental monsoon climate with annual precipitation control of $800 \mathrm{~mm}$ or so. The soil type is mainly cinnamon soil, accompanied by a small area of brown soil, Shajiang black soil and fluvo-aquic soil. In the coal mine area, there are subsidence pits on the ground, and are even subsidence problems. The depth of collapse is between $1 \mathrm{~m}$ and $4 \mathrm{~m}$, and the individual depth is about $6 \mathrm{~m}$. There is a certain security risk of the collapse of the surface caused by uneven surface[3].

First, the relevant project leader in accordance with the project area conditions determines the contours of high distance in the collapse region, and after filling the elevation data, it's rasterized in 
combination with the contours and reference points to launch a suitability evaluation for it. The social post-evaluation of the integrated analysis, planning project and engineering structure are designed mainly for its economic post-evaluation, ecological post-evaluation and social post evaluation.

Second, before the land development and consolidation, the specific problems are analyzed synthetically. Since the area is not large, the difference is not obvious, after the appropriate evaluation, the land is crushed and the analysis is limited factor. First of all, in the process of carrying out the land reclamation project of coal mining, to make a systematic analysis of its ecological post-evaluation by the slope, irrigation and irrigation conditions and cracks and other factors and integrate the dominant factors in the land reclamation project of coal mining subsidence land by focusing on the destruction of the land type and damage. Only by establishing a sound suitability evaluation factor can we integrate and deal with the actual needs of the project to ensure that the research results meet the expectation. In this paper, we analyze the factors that characterize the damage degree of land, the soil stability and the basic quality of the land, and deepen the integration with the analytic hierarchy process. In the next place, we should also integrate the land use status and hydro-geological conditions of the project in the process of data processing and evaluation to provide the guarantee for the characteristics and the conversion precision, and fully integrate the practical problems and management results. The characteristics of the project and the DEM are effectively acquired, and the spatial superposition operation is carried out for different evaluation units. For example, using ArcGIS to classify them. In the mining subsidence land reclamation project, if the value is more than 75 , it is basically suitable; if the value between 50 and 75, it is moderate; if the value between 25 to 50 , it's critically suitable; if the value is less than 25 , it is not suitable. In combination with the relevant level standards, the grade structure of land reclamation project in the mining subsidence area will be determined to generate the evaluation effect map[4].

Thirdly, in order to plan and optimize the project and further improve the evaluation results of the land reclamation project of the coal mining subsidence area, the relevant departments have carried on the calibration in the reclamation area, focusing on the collapsing crushing area, seasonal water area and hilly area Gentle slope area and so on. In other words, during the establishment and operation of the project planning system, the depth analysis and centralized integration are carried out for the specific situation, and the restrictive factors of each region are systematically controlled to improve the economic benefits of land reclamation project.

Fourth, in the process of land reclamation land project, we should deepen the integration of land leveling situation, farmland water conservancy layout parameters and field operation mechanism, so as to maintain the project management appeal and optimize the effect of resource application. The level of lifting the unit and the accuracy of earthwork and so on. It should be noted that, in the process of analyzing the overall structure of the whole structure, the land use potential should be excavated to the maximum extent, and the area of cultivated land should be effectively combined with the specific requirements and post-evaluation parameters. It will provide greater convenience for the agricultural production and to a certain extent, improve the economic value of relevance[5].

Fifth, to implement a post-evaluation mechanism for the coal subsidence land reclamation project after, which includes not only the project decision-making and design objectives of the analysis, but also specific requirements and management practices in order to conduct a comprehensive analysis to ensure that the design standards and practical results meet the requirements and update the stability of the post-evaluation feedback mechanism, laying a solid foundation the coal subsidence land reclamation project quality and comprehensive economic level improvement. In other words, in the process of centralized review and comprehensive control of relevant issues, we should actively implement the specific evaluation mechanism, make a comprehensive evaluation of coal reclamation land reclamation projects, improve the evaluation parameters and awareness, increase the experience at the same time, and effectively enhance China's coal subsidence land reclamation project to bring the economic benefits for the sustainable development of land to provide power. 


\section{Conclusion}

In conclusion, in the process of post-evaluation and analysis of the land reclamation project of coal subsidence land, it is necessary to combine the technical level to carry out the integrated analysis and centralized integration to optimize the effectiveness of the grading evaluation, so as to effectively excavate the land reclamation capacity. The analysis and integration of the whole evaluation structure is carried out by the analytic hierarchy process, which provides theoretical guarantee and practice support for the reliability optimization of the weights data, deepens the integrity of the Post evaluation link, perfects the Land Management Research project and promotes the sustainable development of land resources.

\section{References}

[1] Zhang Qingjun,Lu Junna. Bot Financing and Its Application in Tangshan Mining Subsidence Land Reclamation, Anhui Agricultural Science, 2015,36(33):14731-14732.

[2] Long Fei. Study on Suitability Evaluation of Land Reclamation in Mining Subsidence Area of Holonbuyr Yakeshi Dongshan Coal Mine, Inner Mongolia Agricultural University,2013.

[3] Song Yangrui, Wang Jinman. Organization and Optimization Design of Mining Subsidence Land Reclamation Construction Based on Network Plan, China Coal,2016,42(05):135-139.

[4] Li Xiaowei. Research on Ecological Engineering Reconstruction Technology in Land Reclamation of Mining Subsidence in Typical Plain Area--A Case Study of Zhao Jia Zhai Coal Mine in Xinzheng, Henan Agricultural University, 2016.

[5] Shi Xueyi, Yang Yumin and Meng Fanhua. Comparative Study on Mixing and Stripping Reclamation of Mining Subsidence Ground in Wuyang Mining Area, Coal Journal, 2015,28(04):385-388. 